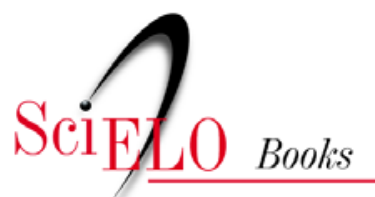

\title{
Profissão médica no Brasil
}

\author{
Pedro Miguel dos Santos
}

\section{SciELO Books / SciELO Livros / SciELO Libros}

SANTOS, P.M. Profissão médica no Brasil. In: MACHADO, M.H., org. Profissões de saúde: uma abordagem sociológica [online]. Rio de Janeiro: Editora FIOCRUZ, 1995, pp. 97-117. ISBN: 978-857541-607-5. Available from: doi: 10.7476/9788575416075.007. Also available in ePUB from: http://books.scielo.org/id/t4ksj/epub/machado-9788575416075.epub.

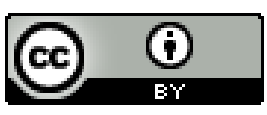

All the contents of this work, except where otherwise noted, is licensed under a Creative Commons Attribution 4.0 International license.

Todo o conteúdo deste trabalho, exceto quando houver ressalva, é publicado sob a licença Creative Commons Atribição 4.0.

Todo el contenido de esta obra, excepto donde se indique lo contrario, está bajo licencia de la licencia Creative Commons Reconocimento 4.0. 


\title{
Profissão médica no Brasil
}

\author{
Pedro Miguel dos Santos
}

\section{Introdução}

A crescente preocupação nos meios acadêmicos brasileiros, que interagem com o movimento social de construção de um modelo de atenção à saúde que cumpra as premissas de resgate de cidadania apontadas na Constituição de 1988 , tem levantado problemas que requerem uma abordagem criativa no sentido de que se superem os entraves ao avanço desta construção.

O posicionamento dos distintos atores envolvidos neste processo tem sido objeto de diversos estudos que levantam para as autoridades do sistema de saúde, e para a sociedade em geral, novos enfoques de abordagem teórica que reclamam uma tradução prática no dia a dia do sistema, principalmente por parte de seus gestores.

A partir desta dificuldade, busca-se, vislumbrando o processo de construção da profissão médica no Brasil, tratar de pontos que parecem fundamentais para a elucidação de posicionamentos destes profissionais que têm suas origens em planos mais subjetivos de sua própria trajetória de afirmação de projeto profissional e que, em última análise, concorrem positivamente ou mesmo negativamente para o avanço das reformas necessárias ao setor.

Neste capítulo aborda-se a consolidação da profissão médica no Brasil e analisa-se a trajetória destes profissionais em nosso meio - levantando-se questões para a reflexão de seus interesses - e, também, faz-se a análise de problemas percebidos por uma parcela de representantes desta categoria profissional, mais exatamente autoridades profissionais das instituições médicas do estado de Pernambuco.

Cumpre alertar que a compreensão das questões levantadas no caso pernambucano (micro) só pode ser alcançada levando-se em conta a influência do processo nacional (macro), e que esta divisão da realidade só 
tem pertinência para a análise mais aprofundada, reconhecendo que a vida das organizações sociais, como as profissões, concretamente não é desconectada de fatores mais gerais que a moldam e a limitam.

\section{Primórdios da profissionalização médica no Brasil: o início da formação de médicos no Brasil}

A medicina adquiriu cunho científico, mais exatamente no século XIX, a partir da introdução dos métodos de produção de conhecimentos científicos. Caso exemplar é o das alterações introduzidas no ensino médico nos Estados Unidos, que influenciou toda a prática e formação médica ocidental. Isto se deu no início do século XX, a partir do que chamamos episódio Flexner, marco de afirmação da nova tendência de formação dos médicos. Naquela época o ensino médico era estruturado de forma incompatível com as novas necessidades de um novo profissional, com capacidade para a intervenção em escala mais ampla nas questões de saúde, exigência imposta pelo desenvolvimento capitalista. O quadro era caótico. Os cursos eram constituídos de forma anárquica, variavam em duração, tinham objetivos distintos e diferentes critérios de admissão. O setor privado promovia a mercantilização desenfreada, buscando daí auferir lucros.

Divulgado em 1910, sob encomenda do governo americano, o relatório Flexner orientava para que este: definisse padrões de admissão para os cursos e ampliação dos anos de formação; utilizasse o ensino nos laboratórios; estimulasse o regime de docência em tempo integral; utilizasse o ensino clínico nos hospitais; vinculasse as escolas médicas às universidades; priorizasse a pesquisa biológica, apoiando a base empírica da prática médica; estimułasse as especializações; promovesse a união do ensino com a pesquisa e, por fim, estimulasse o controle do exercício profissional pela própria corporação médica.

Esta nova versão do ensino médico utilizou a visão mecanicista do objeto profissional, fazendo crer que o corpo fosse divisível em partes, à semelhança de uma máquina. A totalidade corporal passou a ser vista como a soma das partes. A forma de atuar neste novo objeto baseou-se nas ciências que se desenvolviam aceleradamente. A biologia, a física, a química, a citologia, a histologia, a microbiologia e outras, passaram a nortear o combate aos agentes agressores, que se não visíveis ainda, certamente no futuro sẹiam identificados. A individualização do objeto, 
restrito ao corpo dos pacientes, reduziu a visão do coletivo em que os homens se inserem, abolindo a atuação mais epidemiológica da medicina, e de seus profissionais.

Ao ser concebida, na proposta 'cientificista', a medicina como uma ciência, tal qual a física, a quimica e a biologia, que constituem seu suporte, a prática médica é conseqüentemente compreendida como aplicação e produto dessa ciência [...] Reconhecendo nesta identidade metodológica e no desenvolvimento destas ciências-suporte, os elementos básicos que levaram à passagem de uma prática médica 'empírica' para uma prática 'cientificamente fundamentada', a prática médica só poderia ser entendida como indissociável da investigação científica. (Schraiber, 1989)

Esta nova representação de objeto e da forma de atuar sobre ele, moldou o perfil da profissão médica moderna. O médico ganhou dimensões importantes na sociedade, por exercitar tarefas estratégicas na esfera das relações de produção. A manutenção da força de trabalho, a administração do ambiente urbano passaram a ser identificados como temas exclusivos da profissão, que se conformava para tal. Esta conformação da prática e da teoria, bases da profissão médica, deram as qualidades gerais diferenciadoras em relação às demais ocupações.

Diferentemente das ocupações, a profissão assume duas características. A primeira indica que o trabalho profissional é técnico, baseado num sistema de conhecimento ou doutrina adquiridos apenas através do treinamento; a segunda revela que o profissional se adequa a um conjunto de normas profissionais. A base de conhecimento que suporta a profissão tem origem técnica, científica ou ambas. O estudo intelectual especializado, bem como o treinamento têm como finalidade prestar serviços e/ou orientação aos clientes por salário ou pagamento definidos (Carr Saunders, 1966).

No início do século XIX, com a chegada da Coroa, o Brasil passa a ser considerado Reino Unido, representando uma ruptura importante com o panorama anterior. No que refere à formação de médicos, as primeiras mudanças são percebidas a partir de 1808, com a criação da primeira escola de medicina, a Escola de Cirurgia na Bahia, através da Carta Régia de 18 de fevereiro do mesmo ano.

D. João atendia, assim, a uma sugestão de José Corrêa Picanço, cirurgião formado pela Universidade de Coimbra que havia acompanhado a Família Real até o Brasil. Nove meses após, foi criada, também por decreto real, a segunda escola do país a Escola de Cirurgia do Rio de 
Janeiro. Neste mesmo ano, Corrêa Picanço foi nomeado cirurgião-mor do Reino, Estado e Domínios Ultramarinos, assim como o Dr. Manoel Vieira da Silva, nomeado físico-mor. Extinta a Junta de Protomedicato, ${ }^{1}$ instância sanitária criada anteriormente na Colônia por D. Maria $\mathrm{I}^{2}$ passa a ser atributo das duas autoridades nomeadas o poder de instituir bancas examinadoras para a concessão do título de cirurgião ou médico.

O desempenho inicial das primeiras escolas médicas brasileiras parece não ter rompido com a situação anterior, sendo seu desempenho questionado por alguns historiadores da medicina:

Estas duas escolas [...] constituíram apenas os pontos de partida para o ulterior cultivo sistematizado da ciência, eram quanto havia de mais rudimentar e deficiente. Para cursá-las, apenas exigia-se do candidato que êle "soubesse lêr e escrever" e nada mais. Do curso médico-cirúrgico propriamente dito o aluno somente adquiria noções teóricas de anatomia, de fisiologia e de patologia, praticando qualquer coisa de clínica cirúrgica, na Escola Baiana, e estas disciplinas e mais terapêutica e arte obstétrica, na do Rio de Janeiro. [...] as atribuições que tais escolas conferiam a seus alunos eram muito restritas: pouco mais que as fornecidas aos charlatães e meizinheiros pela junta de Proto-medicato, instituição muito poderosa naqueles tempos e que conferia, sem mais delongas, licença a seus afeiçoados para exercerem a medicina em qualquer localidade do Brasil. (Freitas, 1944)

Já em 1813 essas escolas sofrem uma reforma passando a serem chamadas de Colégios Médico-Cirúrgicos, ampliando, inclusive, o número de cadeiras. Em 1826 foi outorgada por D. Pedro I a lei que autorizou as escolas médicas brasileiras a conferirem cartas de cirurgião ou cirurgião-formado e de médico aos alunos concluintes. A partir de 1831, a Regência Trina criou as faculdades de medicina, agora já com 14 cadeiras e 6 anos de curso. Na mesma reforma é constituído o curso de parteiras

1 A Junta de Protomedicato compunha-se de sete membros ou deputados, físicos ou cirurgiões, e de um corpo de funcionários.

2 Santos Filho (1991) descreve assim as funções da Junta de Protomedicato: Os representantes das autoridades reinóis aqui examinavam candidatos às "cartas de examinação" para o exercício de cirurgião-barbeiro e barbeiro, cassavam diplomas e licenças, inspecionavam as boticas, interferiam nos preços das drogas, vistoriavam hospitais, preconizavam medidas de defesa sanitária em tempos de epidemia e fiscalizavam o exercício da profissão por parte dos físicos, cirurgiōes-barbeiros, barbeiros e parteiras. Regiam-se por meio de regulamentos, avisos e alvarás periodicamente expedidos. 
em 2 anos, e o de farmacêutico em 3 anos. Em 1879 ocorre nova alteração nas faculdades de medicina, através da Reforma Leoncio de Carvalho, aumentando para 26 o número de cadeiras. Ao fim do Império, a Reforma Visconde de Sabóia traz uma grande alteração no quadro acadêmico de então, instituindo o curso odontológico, ministrado em 3 anos. Foi permitida a inscrição de mulheres nos cursos médicos, tendo-se como marco a formatura da primeira doutora em medicina, Rita Lopes Lobato, em 1887 , no Rio de Janeiro. Pela primeira vez as mulheres passam a disputar o mercado de trabalho médico.

\section{A defesa do território de trabalho}

Mudaram as condições de formação, mudaram os médicos. Aquela situação inicial dos três primeiros séculos já se encontrava bastante modificada. Um grupo de profissionais aqui formados buscava o fortalecimento de sua corporação, a defesa da profissão e do mercado de trabalho. A partir de 1832, com a lei de 3 de outubro, a reformulação das escolas define claros limites para o exercício da medicina, reconhece a unificação das atividades médicas (cirurgião, boticário e físico), e o direito do exercício profissional para todos os formados nas escolas brasileiras. Assim expressam alguns dos seus artigos:

art. $11^{\circ}$ - As Faculdades concederão os títulos seguintes: $1^{\circ}$ ) Doutor em Medicina, $2^{\circ}$ ) de Farmacêutico, $3^{\circ}$ ) de Parteira. Da publicação desta lei em diante não se concederá mais o título de sangrador. Os diplomas serão passados pelas Faculdades em nome das mesmas, no idioma nacional, e pela forma que elas determinarem.

art. $12^{\circ}$ - Os que obtiverem o título de Doutor em Medicina pelas Faculdades do Brasil poderão exercer em todo o Império indistintamente qualquer dos ramos da arte de curar.

art. $13^{\circ}$ - Sem o título conferido ou aprovado pelas ditas faculdades, ninguém poderá curar, ter botica, ou partejar, enquanto disposições particulares, que regulem o exercício da medicina, não providenciarem a este respeito. Não são compreendidos nesta disposição os médicos, cirurgióes e parteiras, legalmente autorizados em virtude da lei anterior. (Pires, 1989)

A arte de curar passava a ser de competência legal exclusiva dos médicos formados nas faculdades de medicina, ou por elas legitimados. 
Tornam-se profissionais a serem consultados sobre laudos legais, origem de paternidade, autorizações para casamentos, atingindo, assim, posição de destaque na sociedade. A profissão médica, através de vários mecanismos, vai-se transformando e consolidando seu projeto profissional, adquirindo status, autonomia, prestígio e mercado de trabalho.

Este prestígio e poder adquiridos pelos médicos foi fator fundamental para o projeto corporativo. Garantia aderência do Estado e aproximava a profissão dos interesses das classes dominantes. Lembramos outros condicionantes para tal legitimação, estes mais afetos a fatores de determinação estruturais da medicina naquela época, dos quais se utilizavam os médicos. Foucault (1978) descreve-os com precisão:

1 - Aparecimento de uma autoridade médica, que não é simplesmente a autoridade do saber, uma pessoa erudita que sabe referirse aos bons autores. A autoridade médica é uma autoridade social que pode tomar decisões a nivel de uma cidade, um bairro, uma instituição, um regulamento. É a manifestação do que os alemães denominavam Staatsmedicin, medicina do Estado;

2 - Aparecimento de um campo de intervenção da medicina distinto das enfermidades: o ar, a água, as construções, os terrenos, os esgotos, etc. No século XVIII tudo isto se converteu em objeto da medicina;

3 - Introdução de um aparato de medicalização coletiva, a saber, o hospital. Antes do século XVIII o hospital não era uma instituição de medicalização e sim de assistência aos pobres à espera da morte;

4 - Introdução de medicamentos de administração médica: registro de dados, comparação, estabelecimento de estatísticas, etc.

Neste contexto, surge em 1829 a primeira associação médica do Brasil, no Rio de Janeiro, com o nome de Sociedade de Medicina. Participante ativa da estruturação das faculdades de Salvador e do Rio de Janeiro, esta Sociedade mantinha estreitas relações com o poder imperial. Em 1835 foi elevada à categoria de Academia Imperial de Medicina, passando a órgão consultivo do Imperador para assuntos de medicina e saúde pública. Como conseqüência de sua atuação, foram elaboradas leis reguladoras do regime sanitário e o primeiro decreto sobre o exercício legal da profissão médica.

Dando seqüência a esse movimento corporativo, foram criadas outras entidades semelhantes, como a Sociedade de Medicina de Pernambuco em 1841, a da Bahia em 1848 e a Sociedade de Medicina e Cirurgia em 1887, no Rio de Janeiro, todas buscando o aprimoramento científico 
e os aspectos éticos da profissão, bem como o seu fortalecimento junto ao poder constituído. ${ }^{3}$

Ampliando a estrutura de representação e organização dos médicos brasileiros, surge em 1927, no Rio de Janeiro, o primeiro sindicato, denominado Sindicato Médico Brasileiro. O contexto da época, com o surgimento do movimento operário nas grandes cidades, o deslocamento para o espaço urbano de grandes parcelas de população, e a necessidade de organização por parte dos segmentos de trabalhadores por melhores condições de vida, fez com que as chamadas profissões liberais se mobilizassem em busca de uma representação mais atuante no campo econômico. O Sindicato Médico Brasileiro constituiu-se no primeiro sindicato de profissionais liberais do Brasil.

Desde sua fundação, o Sindicato Médico Brasileiro tinha como um de seus propósitos organizar um Código de Deontologia. Após o II Congresso Médico Latino-Americano, realizado em Havana em 1926, foi publicado em um de seus boletins, o Código de Moral Médica, que, porém, não conseguiu ser aplicado de fato como referencial para a organização ética da categoria.

Em 1945 foi criado, através do decreto-lei 7.955, o Conselho Federal de Medicina, colocando em vigor o Código de Deontologia Médica. A criação deste conselho havia sido sugerida pelo IV Congresso Médico Sindicalista. Segundo Marinho (1986):

A lei impunha ingerência ainda maior do poder executivo na organização médica que se formava, não só a escolha dos membros do conselho provisório estava a cargo do Ministério do Trabalho, Indústria e Comércio, mas também instituía um elemento estranho à classe, sem as devidas qualificações e vínculos profissionais, como árbitro nas questões de ética médica.

No artigo $14^{\circ}$, o decreto-lei expressava:

Ao Ministro do Trabalho, Indústria e Comércio incube decidir sobre os casos omissos e as dúvidas suscitadas na execução do decreto-lei. (Ramos, 1974)

3 Tanto as academias ou escolas de medicina do Rio de Janeiro ou da Bahia, como a Sociedade ou Academia Imperial, representam a corporação médica, e é através delas que o grupo médico tenta aproximar-se do poder, oferecendo uma estratégia de organização do espaço urbano, insalubre, poluído de "miasmas" e epidemias (Pires, 1989). 
Esta intervenção foi repudiada pela categoria médica, que, por vários mecanismos de pressão, trabalhou contra a efetividade das ações do Conselho. Um deste mecanismos foi a criação da Associação Médica Brasileira (AMB), em 1951. Com características de federação nacional das associações estaduais, a AMB levantou a bandeira da mudança do decreto 7.955, o que ocorreria em 1957 pela lei de número 3.268, que regulamenta a atual estrutura dos conselhos da categoria médica. Cria-se a estrutura do Conselho Federal de Medicina, localizado no Distrito Federal, e os conselhos regionais em cada unidade federativa. Estes conselhos são definidos como órgãos supervisores da ética profissional, julgadores e disciplinadores da classe médica. Adquirem, a partir daí, os conselhos federal e regionais, autonomia administrativa e financeira.

Reduziu-se o espírito intervencionista do Estado, passando para o próprio Conselho as atribuições finais de julgamento ético da categoria, adquirindo esta o direito de compor este Conselho Nacional, devendo eleger dez membros efetivos e seus respectivos suplentes. Entre estes, nove membros são eleitos por escrutínio secreto pelos delegados regionais. O restante da diretoria é eleito pela Associação Médica Brasileira, entidade que congrega as sociedades de especialidades médicas.

Apesar desta nova configuração, o conselho sempre teve forte ligação com o Estado. Sua idealização teve origem no pós-guerra, quando se discutia sobre os deveres estatais que não deveriam ser restritos apenas à direção política e administrativa da nação. Deviam ser ampliados tendo como perspectiva o maior controle da sociedade. Segundo Ramos (1974), esta discussão tinha como base o modelo implantado na Itália e Alemanha, onde haviam sido criadas as Ordens Médicas nos anos anteriores à Segunda Guerra Mundial.

No nível dos conselhos regionais são definidas como atribuições:

Manter um registro dos médicos legalmente habilitados, com exercício na respectiva região; fiscalizar o exercício da profissão médica: conhecer, apreciar e decidir os assuntos atinentes à ética profissional, impondo as penalidades que couberem; promover, por todos os meios ao seu alcance, o perfeito desempenho técnico e moral da medicina e o prestígio e bom conceito da medicina, da profissão e dos que a exerçam; velar pela conservação da honra e da independência do conselho, e pelo livre exercício legal dos direitos dos médicos. (C. R. M. PE, 1985)

Durante o regime militar, a década de setenta marcou no movimento médico brasileiro um período de lutas. Nos sindicatos surge o REME 
(Movimento de Integração e Renovação Médica), colocando estes profissionais na luta por melhores condições de atendimento e assistência à população.

O REME caracterizou-se por uma visão contrária às das parcelas mais conservadoras da categoria, ocupantes das entidades da corporação, tendo como pano de fundo o reconhecimento do assalariamento da maioria dos médicos. ${ }^{4} \mathrm{O}$ movimento opunha-se ao regime militar, exigindo o reconhecimento dos direitos trabalhistas e aliando-se às lutas gerais dos trabalhadores. Como meta, propunha a reconstrução das entidades médicas, vistas como inoperantes ou atreladas ao regime. Nesta discussão se abordava a necessidade de alteração do Código de Ética então em vigor. Paulatinamente o REME ampliou seus espaços conquistando direções de entidades, primeiramente nos estados onde a discussão política era mais presente, como os estados do sudeste. Posteriormente atingiu outros locais, ampliando a organização dos médicos à medida que o regime militar dava sinais de fraqueza.

Em 1984 a luta pela alteração do código de ética foi atingida, substituindo o Código de Ética Médica de 1965, pelo atual Código Brasileiro de Deontologia Médica Resolução C. F. M. n ${ }^{0} 1.154 / 84$. Neste código os profissionais expressam princípios que tratam da afirmação do ideal de serviço, declarando sua responsabilidade para com os pacientes e a sociedade; procuram disciplinar-se no mercado, apontando para uma relação de harmonia entre os pares; promovem o desenvolvimento da profissão a partir do progresso científico desta; assumem a autonomia afirmando condições para o exercício profissional; pactuam quanto ao segredo profissional, comprometendo-se na defesa da profissão e dos pares.

Atribuindo a visão de Wilensky (1970) à trajetória da profissão médica no Brasil, observamos que o processo de profissionalização se constituiu dos seguintes elementos:

Inicialmente, as práticas de saúde desenvolvidas tanto na esfera pública quanto na esfera privada foram se deslocando do grupo de práticos que detinha menores domínios de saberes e técnicas, para aquela parcela mais aplicada nas ações de destaque para a clientela. Estas práticas se

4 Contudo se os Kassabistas (ala conservadora do movimento médico, assim intitulado por ter em Pedro Kassabi um de seus principais representantes) viam os médicos enquanto profissionais liberais trabalhando em regime de autonomia, o REME os via como assalariados, não reconhecendo a heterogeneidade de formas de inserção da categoria no mercado de trabalho $e$, que se refletia na multiplicidade dos seus interesses e problemas. (Souza Campos, 1988) 
fizeram acompanhar da necessidade crescente pelo tipo de serviço que representavam.

Aliada às transformações políticas do Estado Brasileiro, emergiu a demanda por uma formação mais adequada dos profissionais que atuavam na Colônia. O surgimento das escolas médicas acelera a estruturação deste grupo, que se organiza numa associação nacional para lutar por seus interesses e intervir na própria formação dos novos membros. Fundiramse as habilidades e campos de intervenção dos cirurgiões e físicos num mesmo profissional, o doutor em medicina.

A proteção legal do território de trabalho ocorre a partir da interação dos médicos com as esferas do poder público, visando inibir a prática dos curiosos e afins, que anteriormente atuavam em pé de igualdade no mercado. As escolas passaram a promover a diferenciação na qualificação de seus formandos, obedecendo aos preceitos legais de exclusividade de competência para os médicos.

O associativismo da categoria médica cumpriu o papel de organização dos interesses específicos, inicialmente trabalhando em nível nacional, e à medida que a profissão se estruturou, ampliou-se para as regióes e estados. Em sua última etapa de profissionalização, os médicos instituíram o código de ética, de abrangência nacional, conformando definitivamente a face profissional da categoria.

\section{Desafios atuais à profissão médica: o caso da conjuntura pernambucana}

Constatamos a existência de fatores que representam dificuldades para a continuidade do profissionalismo médico, compreendido da forma como vínhamos discutindo até agora.

A formação dos profissionais segue apontando para a especialização precoce. Especialização esta exigida pelo mercado, que se orienta para a prestação de serviços que envolvam maior aplicação de capital, com uso direto de tecnologia complexa, principalmente na etapa de diagnóstico durante o ato médico. Tal mercado não atinge a maioria da população de baixa renda, necessitada dos serviços de saúde. Se isto é negativo para a clientela usuária, também é identificado como um fator de crise para o projeto profissional dos médicos.

Poderíamos imaginar que para problemas de tal natureza, a profissão pudesse desenvolver alternativas de redirecionamento em sua prática 
profissional, reestruturando o seu projeto de grupo coeso em suas afirmações de profissionalismo, resgatando sua premissa de serviço. Esta alternativa não se expressa na prática, pois fatores que já não dependem exclusivamente do universo profissional atuam em direção contrária, reduzindo sua possibilidade de readaptação. Em relação a isto, afirma Schraiber (1989):

... deveria a escola antes de mais nada desenvolver a compreensão do indivíduo como um todo nos profissionais que qualifica, e assim capacitá-los tecnicamente à base de atitudes correlatas a uma tal compreensão. Para tanto, porém, far-se-ia necessário reformular o padrão educacional existente. Este, ao configurar uma capacitação técnica restrita a conhecimentos parcelares, fruto da crescente especialização no conhecimento médico, ao configurar uma capacitação centrada em conhecimentos tão-somente biológicos, e ainda afastada das condições de vida do paciente (dado o seu desenvolvimento basicamente hospitalar), oferece uma qualificação fragmentada, impossibilitando assim a compreensão do indivíduo globalmente...

Ocorre que, desde o momento da formação, a profissão médica enfrenta o dilema entre a afirmação do discurso de serviço, quase sacerdotal, e o chamamento dos ganhos mais altos, provocando o que algumas representações da categoria chamam de perda de referência profissional. ${ }^{5}$ Esta perda tem sido definida como um desestímulo ao melhor desempenho no espaço de trabalho. Para essas lideranças, a tendência à especialização promove um afastamento dos princípios mais propalados na formação.

O especialismo imprime na prática médica limites à sua autonomia e antiga independência diante das situações cotidianas. $O$ médico que, mesmo na casa do paciente, podia solucionar muitos problemas, distancia-se desta possibilidade, requerendo progressivamente o apoio de uma estrutura complexa, normalmente hospitalar, onde estarão à disposição exames e tecnologia que sozinho é incapaz de manter. Como sua formação é primariamente a de um especialista, não há muitas condições onde a criatividade possa auxiliar na ruptura dessa dependência. Considerando tal discussão, Bittar (1991) afirma:

O que deve ser evitado é que a especialização (principalmente a subespecialização) leve à formação precoce de especialistas, o que é

5 Expressão utilizada por lideranças sindicais e da sociedade científica médica em Pernambuco durante o período de entrevistas que serviram de subsídio para este estudo, 1992. 
estimulado através da criação de áreas específicas de ensino e treinamento em faculdades e mesmo nas estruturas organizacionais dos hospitais e, também, como lembra Del Castillo, a multiplicação de especialidades não só limita a uma área o campo da medicina, às vezes a uma técnica, com o que fragmenta em excesso o exercício médico $e$ marginaliza a medicina integral, a que atende o indivíduo como organismo, como ser humano.

Superar essa situação está longe de vir a ser real. Se fosse tão simples bastaria, ao nosso ver, a via da reforma curricular como solução. Há algum tempo já teríamos observado modificações que visassem a redução do chamado currículo paralelo, desenvolvido pelos estudantes em espaços extra-acadêmicos, necessários àqueles que pretendam entrar mais rapidamente no mercado após a conclusão de sua formação. Também se teria atuado na, sempre denunciada, baixa qualidade dos cursos médicos.

Esse quadro leva ao fortalecimento dos programas de pós-graduação, lato sensu (leia-se residência médica), que se transformam, de fato, numa continuidade da graduação, onde, mais do que a especialização, ainda se pretende que cubram lacunas da formação. Estes programas têm, aos poucos, sido assumidos pelo mercado, tanto público como privado, enquanto critério de qualificação para o desempenho profissional. O trabalho médico daí oriundo será necessariamente parcelado, voltado para tarefas bem delimitadas, exclusivas, aquelas que não apontam para a reintegração do profissional diante do seu objeto. Confirmando a tendência de aumento dos programas de residências, vemos que em 1988 o Relatório Geral da Comissão Nacional de Residência Médica (Bittar, 1991) demonstra que o Brasil possuía 48 tipos distintos de programas de residência, compreendendo as mais diversas especialidades.

Contraditório com o ideal de serviço mas não com a lógica de acumulação do capitalismo, o alto custo que o modelo da medicina científica impõe para sua efetivação, ao qual a profissão se adaptou, é cada vez mais questionado quanto ao seu poder de resolutividade, diante da grande soma de capital necessária à sua execução. A este respeito Singer (1988) afirma:

O avanço da tecnologia médica [...] resultou em impressionante sofisticação do aparel hamento, o que se traduz no aumento do volume de trabalho social dispendido em sua produção. Convém notar que boa parte desta sofisticação tem por fim aperfeiçoar a capacidade de diagnosticar enfermidades cuja cura ainda se desconbece, de modo que sua utilidade quanto à melhoria do estado de saúde da população é 
duvidosa. O mesmo pode ser dito da multiplicação de remédios, a maioria dos quais se destinam a aliviar sintomas de males que a medicina não consegue prevenir nem curar.

Esta prática encontra uma relação custo versus benefício desfavorável, representando um conflito de difícil solução para os médicos. Se sua atuação é cada vez mais julgada e, talvez num crescente, considerada dispendiosa e ineficaz, o que se atinge fundamentalmente é o núcleo de sua identificação e autoridade pela clientela, que não dissocia - e nada sugere que venha a ocorrer - o profissional médico da parafernália da qual está sendo ao mesmo tempo operador e vítima.

O mercado de trabalho estabelece grandes desafios para o profissionalismo médico. Nas discussões promovidas por representantes da categoria local são apontadas dificuldades na organização dos interesses da categoria de ordem mais geral. Uma delas é que o mercado de trabalho se orienta pelo pagamento de procedimentos, diferenciando aqueles mais onerosos dos mais simples, criando uma pressão para que os profissionais modifiquem sua prática introduzindo exames, técnicas e medicações mais caras, o que os credencia a ganhos mais altos do que os que teriam com terapêuticas menos dispendiosas.

Por outro lado, a política setorial questiona progressivamente os interesses corporativos mais tradicionais. A demanda por mais ações, executadas com maior resolutividade e eficácia, tem utilizado o critério de produtividade nos serviços de saúde. Não é por coincidência que isto é denunciado como um fator de descaracterização profissional por parte das representações políticas médicas. Apesar das resistências e de um ou outro percalço que tal política possa sofrer, inclusive pela oposição dos profissionais, é provável que o critério da racionalização dos serviços, onde a preocupação com custos e benefícios esteja presente, tenda a continuar, encontrando os médicos com grandes dificuldades de adaptação. Como negar a importância de tal postura para a ampliação do acesso aos serviços de saúde por parte da sociedade sem atingir diretamente o trabalho médico?

A atuação do Estado no mercado de trabalho, com forte afluxo de capitais, a partir das necessidades de ampliação da cobertura dos serviços e da própria pressão da população, que vai se tornando consumidora exigente de um padrão mais afeito às suas necessidades, agem de forma decisiva na profissão, provocando efeitos não previsíveis em seu projeto histórico. Com a grande circulação de recursos, despertam, os médicos, de forma crescente, para a criação de serviços privados onde passam a 
empregar colegas, assumindo uma postura gerencial e administrativa semelhante ao raciocínio empresarial. Por outro lado, os médicos empregados se movem a partir de interesses mais econômicos, reconhecendo seus empregadores como distintos em seus objetivos profissionais. Esta contradição não parece ter solução em breve tempo, e como conseqüência tem determinado uma certa estratificação entre os profissionais, surgindo conflitos de interesses inegáveis. Outra repercussão desta diferenciação promovida pelo mercado atua como uma elitização entre os profissionais, onde existem poucos médicos que auferem renda muitas vezes maior do que o restante da categoria, não havendo grande diferença entre os mercados público e privado. A grande maioria dos médicos pernambucanos tem, em última análise, o setor público como fonte de seus vencimentos.

Lembramos, como uma das principais fontes deste desvio, a forma de pagamento por procedimentos, tanto nos hospitais públicos como nos contratados. Mesmo quando os médicos detêm vínculos com tais organizações, esta forma de pagamento, seja o procedimento, seja a produtividade, estimula a busca por maiores ganhos, afastando-os dos princípios éticos da profissão.

Com a burocratização das organizações de saúde o médico enfrenta, cada vez mais, a perda de autonomia. A progressiva redução do mercado tipicamente autônomo, colocando os médicos nas instituições de seguridade, aceitando as formas de pagamento por procedimento e acatando a clientela indicada por tais agências de seguro, apontam para a redução da autonomia e identidade do projeto profissional. Não é demais lembrar que o setor público orienta-se pela readaptação de seu modelo gerencial, buscando muitas das vezes a agilidade empresarial tanto no discurso de seus administradores, quanto na nova rotinização das atividades. O patrão público começa a ter preocupações típicas dos empresários privados, o que pode ser percebido em recente discussão da descentralização das emergências do SUS/PE.

Ocorrem outros desvios profissionais. Dos mais lembrados é o descaso dos médicos para com as condições de trabalho. Não é mais importante a qualidade do local de trabalho, a manutenção dos equipamentos, havendo dificuldades de se observar o código de ética em condições precárias de trabalho, tanto no serviço público como no privado. Os deveres para com os pacientes se chocam com a impossibilidade dos profissionais de transformarem o espaço de trabalho, restando a inconformidade com o próprio desempenho.

Com todos estes fatores ocorrendo, não é à toa que as lideranças da 
categoria denunciam um esvaziamento das entidades profissionais. Do sindicato à sociedade esta realidade está presente. Como exemplos mais representativos deste afastamento cumpre realçar alguns.

Para a ełeição da direção sindical médica em Pernambuco no ano de 1992 convocou-se por duas vezes a inscrição de chapas, o que não se verificou. Surpreendentemente, foi necessário compor uma junta governativa para seguir com as atividades da entidade. Dos cerca de dez mil médicos atuantes nos estado apenas 34\% era filiado ao sindicato. ${ }^{6}$

Observamos uma tendência à diminuição da atividade sindical exclusivamente médica, que não deve ser encarada como um fortalecimento das atividades das outras organizações profissionais. Talvez a explicação para isto não seja encontrada no espaço sindical da categoria. O que vem ocorrendo, na prática, é que os médicos iniciam uma aproximação com outros trabalhadores do setor, participando das lutas de forma coletiva, buscando ganhos para seus interesses econômicos, a partir das mobilizações mais gerais, de base setorial. Isto tem colocado em jogo o sentido mais profissional da autorepresentação, afastando os médicos de seu projeto histórico, enquanto corporação. Na verdade, os sindicatos exclusivos de categoria têm tido cada vez mais um menor poder de pressão e barganha junto ao mercado público ou privado, impondo-se como alternativa para os trabalhadores a articulação setorial de sua representação.

Por outro lado, a Sociedade de Medicina de Pernambuco também enfrenta grandes dificuldades. É consenso em sua direção que as sociedades filiadas de especialidades congregam a maior parte dos médicos pernambucanos, esvaziando a representação da sociedade mãe (termo utilizado pelos diretores). As sociedades de especialidades não agem conjuntamente. Têm objetivos distintos, voltados para a discussão de seus interesses mais restritos. Comprovando o que o especialismo provoca no espírito profissional dos médicos, que passam a atuar como profissionais que já não possuem uma identificação recíproca, geral, de objeto único. A mediação entre a categoria só se realiza em momentos muito específicos, cada vez mais reduzidos.

O último congresso médico de Pernambuco foi considerado esvaziado pelos diretores das entidades. Ao mesmo tempo, os congressos de especialidades, quando ocorrem, são dirigidos aos médicos que podem pagar, retornando o que aqui foi chamado de elitização entre os médicos.

Em nível do conselho de ética ocorrem outras dificuldades para o

6 Dados fornecidos pelo Sindicato, relativos a janeiro de 1993. 
desempenho do projeto profissional. Lembramos que em termos de condições materiais e financeiras esta entidade tem a melhor situação entre as demais da profissão. Como é obrigatória a inscrição dos médicos para o exercício da medicina, isto garante um ingresso permanente de recursos para o custeio da entidade. O conselho tem a atribuição de fiscalização dos profissionais, sendo difícil promover-se o controle do trabalho médico sem que sejam levadas em conta a situação dos locais de trabalho, compreendendo aí todas as organizações prestadoras de serviços de saúde, sejam públicas ou privadas. O conselho não pode executar ações de punição a tais serviços. Seu papel fica restrito à denúncia e à recomendação, sendo necessária a participação e acordo do poder público para que se efetivem medidas punitivas.

Assim é que na Resolução 1.089/1982 do Conselho Federal de Medicina são estabelecidos limites para a atuação de controle e fiscalização do exercício profissional. No capítulo das competências temos o seguinte:

Art. $4^{\circ}$ - Ao órgão de Fiscalização compete, em todo o território da jurisdição do Conselho Regional respectivo:

I-Fiscalizar:

a-O exercício da profissão de médico, em qualquer local onde seja desempenhada;

b-Os organismos onde os médicos prestam serviços, na parte exclusivamente médico-assistencial;

c-Os anúncios de médicos ou de serviços de assistência médica, qualquer que seja o meio de comunicação;

$d$ - O conhecimento das notificações.

Se essa formulação sugere uma capacidade ainda real de controle do trabalho médico, observamos que a mesma resolução assume limites para a fiscalização do local de trabalho onde os médicos se encontram, colocando, ao nosso ver, uma contradição fundamental para a autonomia da profissão. Como abstrair o local de trabalho da avaliação de qualidade do trabalhado? Sem resposta para isso a corporação admite que deve:

Providenciar no sentido de notificar às autoridades competentes o exercício ilegal da medicina; - Acompanhar e colaborar com a apreensão, pela Polícia Judiciária ou Sanitária, dos instrumentos e tudo o mais que sirva ou tenha servido ao exercício ilegal da profissão de médico, inclusive participando do auto de fechamento e interdição de tais lugares:

Denunciar ao Conselho (federal) ou outras autoridades com- 
petentes as irregularidades encontradas e não corrigidas deniro dos prazos.

Parágrafo Único - O órgão de fiscalização procurará sempre agir em conjunto com o Serviço de Fiscalização da Secretaria de Saúde ou órgão similar. (Resolução 1089/82 do C. F. M.)

Vemos assim que a atribuição de fiscalização é partilhada com o poder público, tendo até uma característica de dependência, já que a categoria não pode levar às últimas conseqüências o controle do exercício da profissão sem que haja a anuência das autoridades competentes.

Algumas das dificuldades pelas quais passa o profissionalismo médico em sua autonomia, autoridade, independência, e coesão de grupo, podem ser compreendidas como fatores conjunturais cujos efeitos podem ser reduzidos a partir de modificações sociais amplas. É possível que as condições de trabalho melhorem ao ponto de que a atividade médica não seja exercida em condições desfavoráveis ao desempenho dos seus profissionais. Outros fatores, porém, aqui ligeiramente discutidos, são em sua essência de natureza estrutural às sociedades contemporâneas, onde o capital toma sua forma monopolista. Esses, e nada faz crer no contrário, tendem a se radicalizar, levando sua marcha ao comprometimento do lado mais romântico do profissionalismo médico.

\section{Algumas considerações finais}

A sociologia tem alertado para a possibilidade de que esteja havendo uma proletarização dos médicos. ${ }^{7}$ Para não discutirmos, a partir daí, o que necessariamente exigiria a discussão do que vem a ser um proletário nas sociedades modernas, admitimos que fatores intra e extraprofissionais atuam hoje colocando para os médicos dificuldades importantes na sua conformação de profissional típico.

Uma das correntes explicativas das transformações que têm abalado o profissionalismo médico sugere que esteja ocorrendo, de fato, uma trajetória de desprofissionalização, que pode ser representada como oposta aos caminhos que a profissão percorreu até os dias de hoje em sua afirmação profissional. Entre os obstáculos ao projeto profissional, a tendência à burocratização nas organizações dos serviços de saúde é um deles. Com a crescente complexificação do ato médico, este passa a ser dividido em par-

7 Mckinlay, J. \& Arches, J., 1986. 
tés administráveis por outras profissões e ocupações, parcelando o trabalho médico com progressiva redução da sua autonomia. A crescente especialização dos serviços reforça esta redução, o que parece inevitável.

Nas organizações complexas, como os hospitais de especialidades, o trabalho médico tem se tornado, num momento, parte de todo um fluxo desenvolvido por uma equipe multiprofissional, que atua desde a recepção aos pacientes até a parte típica de hotelaria. Os profissionais dependem de outros trabalhadores para que seu trabalho seja executado. Os distintos trabalhos desenvolvem, cada vez mais, um conhecimento específico, uma forma de ser própria, conformando habilidades nos executores que progressivamente retira dos médicos o conhecimento global do que ocorre em torno do ato de prestar saúde.

Mesmo quando a tarefa administrativa dessas organizações é desempenhada por médicos, ocorre o afastamento de sua natureza profissional, não devendo tal espaço ser considerado como próprio das atribuições profissionais originais. Além disto os administradores tendem a desenvolver um projeto com interesses próprios, com auto-representação e identidade cada vez mais nítida e distante do controle por parte de outros trabalhadores envolvidos no processo de trabalho, aí incluídos os médicos.

Também tem sido uma constante a preocupação com a entrada da tecnologia computadorizada no trabalho de saúde. Por mais futurista que isto possa parecer, não deve ser desprezada a modificação das rotinas no trabalho médico com a incorporação de tal tecnologia. Haug (1988), em relação a isto, chega a afirmar:

Num periodo em que estudantes do segundo grau operam PCs na escola, pode estar chegando o tempo em que o importante não seja mais quem detém a informação no cérebro, mas aquele que pode extrair esta informação da memória do computador.

Mudanças na clientela reforçam a possibilidade de desprofissionalização dos médicos. A ampliação e maior domínio da informação pela sociedade vêm lentamente forjando uma consciência crítica e reivindicatória quanto aos serviços de saúde. Essa informação, às vezes deturpadamente, atribui muitas das aflições pelas quais passam os usuários, aos médicos que não atendem bem, não querem prestar o melhor serviço etc. Obviamente, não há profissão sem autoridade profissional, e esta tem sido constantemente desafiada. Cada vez mais põe-se em dúvida o desempenho médico, o que pode ser verificado quando são discutidos ampla- 
mente os erros médicos. Este debate, antes restrito à categoria, generaliza-se, ocupando outros espaços como os tribunais de justiça.

A introdução de formas distintas de práticas de saúde, diferentes do modelo da medicina científica, tem também servido de alerta para aqueles que estudam o (des) profissionalismo médico. As práticas tidas como alternativas, como a acupuntura, a homeopatia, a medicina natural e outras, colocam para os usuários um leque maior de opções diante de suas necessidades, sem que o médico, e a racionalidade por ele representada, sejam necessários à sua execução.

Essa corrente sociológica, que discute a desprofissionalização médi$\mathrm{ca}$, aborda outra série de fatores que indicam desafios à profissão que, pela sua abragência, nosso texto não pode comportar. Deixamos claro que não desconhecemos a importância da continuidade desta investigação, para o que entendemos ser imperativo um maior envolvimento das entidades profissionais médicas, bem como de seus representados. Que se tente estabelecer um ponto inicial de referência para a melhor compreensão dos recuos e avanços do projeto profissional médico e as repercussões disto para a prestação de serviços de saúde.

\section{Bibliografia}

ASSOCIAÇÃO BRASILEIRA DE ENSINO MÉDICO. Anais do XVII Congresso, Poços de Caldas, 1979. . Anais do XVIII Congresso, Goiânia, 1980.

ACADEMIA PERNAMBUCANA DE MEDICINA. Anais, Recife, v. 1, 1974. . Anais, Recife, v. 2, 1976.

BAREMBLIT, G. Saber e poder: que hacer y deseo. Buenos Ayres, Nueva Vision, 1988.

BITTAR, O. J. N. Especialidades médicas no Brasil. In: Previdência em Dados, 6 (1), Rio de Janeiro, 1991.

CARR SAUNDERS, A. M. Professionalization in historical perspective. In: Vollmer, H. \& Mills, D. (eds.). Professionalization, Prentice Hall Inc., New Jersey, Englewood Cliffs, 1966.

CREMEPE, Legislação dos Conselhos de Medicina. Código Brasileiro de Deontologia Médica, Recife, 1985.

DONNANGELO, M. C. F. Medicina e Sociedade. São Paulo, Livraria Pioneira Editora, 1975.

. Saúde e Sociedade. 2a ed., São Paulo, Duas Cidades, 1979. 
FOUCAULT, M. La crisis de la Medicina o la crisis de la antimedicina. In: Medicina e história: El pensamiento de Michel Foucault. Washington D. C., OPAS/OMS, 1978.

. História de la medicalizacion. In: Medicina e história: El pensamiento de Michel Foucault. Washington D. C., OPAS-OMS, 1978.

Incorporacion del hospital en la tecnologia moderna. In: Medicina e história: El pensamiento de Michel Foucault, Washington D. C., OPAS/OMS, 1978.

. O Nascimento da clínica. Rio de Janeiro, Forense Universitária, 1980. - Microfísica do poder. $8^{\text {a }}$ ed., Rio de Janeiro, Graal, 1989.

FREIDSON, E. La profession médica. Barcelona, Ediciones Península, 1978.

FREITAS, O. de. História da Faculdade de Medicina do Recife: 1895 a 1943. Recife, Imprensa Oficial do Recife, 1944.

GONÇALVES, R. B. M. Medicina e história: raíces sociales del trabajo médico, México, Siglo Veinturno Editores, 1984.

GREENWOOD, E. Atributes of a profession. In: Vollmer, H \& Mills, D. (eds.). Professionalization, Prentice Hall Inc. New Jersey, Englewood Cliffs, 1966.

HAUG, M. R. A re-examination of the hypothesys of physycian deprofissionalization. In: The Milbank Quartely. vol. 66, suppl. 2, Milbank Memorial Fund, 1988.

HUGHES, E. The profession in society. In: Vollmer, H \& Mills, D. (eds.). Professionalization, Prentice Hall Inc. New Jersey, Englewood Cliffs, 1966.

LARSON, M. S. The rise of profissionalism: a sociological analisys. Los Angeles, University of California Press, 1977.

MACHADO, M. H. Micro-macro: os novos desafios da sociologia. Rio de Janeiro, 1990. (mimeo)

MARINHO, M. J. Profissionalização e credenciamento: a política das profissões. Rio de Janeiro, Senai, 1986.

NOGUEIRA, R. P. Medicina interna e cirurgia: a formação social da prática médica. Tese de Mestrado, Rio de Janeiro, IMS/Uerj, 1977.

OPAS Medicina e história, El pensamiento de Michel Foucault, Washington, D.C., OPAS/OMS, 1977.

OPAS/AMS/IBGE. Postos de trabalho em saúde no Brasil e Pernambuco, 1976-84, 1984.

PIRES, D. Hegemonia médica na saúde e a enfermagem. São Paulo, Cortez, 1989. RAMOS, J. Ética médica. Rio de Janeiro, Cremeg, 1974.

SANTOS FILHO, L. História geral da medicina brasileira, vol. 1, São Paulo, Hucitec, 1991.

SANTOS NETO, P. (org.) Dinâmica organizativa das corporações de saúde em Pernambuco. Projeto de Pesquisa. Recife, Nesc/CPqAM/Fiocruz, 1991. (mimeo)

SCHRAIBER, L. B. Educação médica e capitalismo. São Paulo-Rio de Janeiro, Hucitec/Abrasco, 1989. 
SINGER, P. et al. Prevenir e curar. Rio de Janeiro, Forense Universitária, 1988. SOUSA CAMPOS, G. W. Os médicos e a política de saúde. São Paulo, Hucitec, 1988.

STARR, P. The social transformation of americam medicine. New York, Basic Books Inc. Publishers, 1982.

WILENSKY, H. The Profissionalization of everyone?. In: Grusky, Oscar \& Miller, George (eds.). The sociology os organization. London, Collier Macmillan, 1970 . 